\title{
Temperature Development of Cardboard in Contact with High-frequency Vibrating Metal Surfaces
}

\begin{abstract}
Albrecht Löwe,* Marek Hauptmann, André Hofmann, and Jens-Peter Majschak
The heating of cardboard was studied when it is in contact with ultrasonic sonotrodes, whose vibrations were orientated parallel and perpendicular to the material surface. The parameters that were varied included the contact pressure on the sonotrode, vibration amplitude, and moisture content of the material. It was shown that there was a major decrease in the contact pressure shortly after the beginning of the experiment when the gap between the sonotrode and anvil was kept constant and thus a decrease in the temperature gradient of the material occurred. With parallel vibration, the material heated up from the sonotrode side, whereas heating started from the center of the material in the case of vertical vibration. This suggested that in cases of vertical vibration, heat is mostly generated by internal dissipation, and in cases of parallel vibration, heat is generated by friction losses on the surface. Furthermore, the results revealed the influence of the parameters on the initial temperature gradient, the maximum temperature, and the moisture content of the material.
\end{abstract}

Keywords: Paperboard; Ultrasonic vibrations; Heating

Contact information: Chair of Processing Machines and Processing Technology, Technische Universität Dresden, Bergstraße 120, 01069 Dresden, Germany;

*Corresponding author: albrecht.loewe@tu-dresden.de

\section{INTRODUCTION}

Cardboard as a material for cups and trays is a widely used alternative to fossil raw materials. Packages with a low degree of deformation, such as food trays or paper plates, are produced by embossing, whereas higher vessels usually consist of multiple parts (bottom, wall, banderole where appropriate), which means a relatively high effort compared to the manufacturing from a single part. Here, deep-drawing is a useful option for producing such packages in only one step from a single sheet of cardboard. Significant improvements of the quality and the format variety of the formed parts have been achieved in recent years in numerous research papers (Hauptmann 2010; Hauptmann 2017) The research on deep-drawing of cardboard has so far focused exclusively on rigid, heated tools, whereas the metal sector has also used ultrasonic tools with remarkable results. This publication is intended to contribute to the research of deep-drawing of cardboard with ultrasonic tools.

When designing tool sonotrodes for deep-drawing, the expected heating of the cardboard in contact with these sonotrodes is of considerable interest. The modulus of elasticity of the polymeric components of the cardboard (cellulose, hemicelluloses, and lignin) and also that of the paper itself depend on the material temperature (Sperling 2006). By heating a material, it is possible to noticeably improve its formability. Furthermore, the dynamic coefficient of friction decreases with increased contact temperature (Niskanen 1998; Lenske et al. 2017). The results of the investigations presented here can also be used 
for other forming processes, such as calendering and joining. However, the results relate primarily to deep-drawing and, more precisely, to the heating of the material in the gap between the die and punch. The distance between the tools is determined by the inner diameter of the die and the outer diameter of the punch and cannot be modified during the process. Therefore, the pressure during the experiments is not adjusted by increasing or decreasing the tool distance.

In the plastics industry, research into heating by contact with high frequency vibrating surfaces has progressed well because of numerous industrial applications, such as ultrasonic welding and sealing of plastic packages. There are fewer scientific publications on the heating of paper and cardboard, but the investigations into thermoplastics could be considered relevant for the paper sector, because of their similarities. A detailed comparison of the cardboard used in the experiments and four common thermoplastics can be found in the appendix. Hereafter, some sources for vibration vertical and parallel to the material surface are discussed.

For vertical vibration, the following studies have been conducted. During ultrasonic welding of polyethylene (PE), Chernyak (1973) measured the temperature at the contact surface of a sonotrode and workpiece and inside of the workpiece. It was found that the entire cross section was heated uniformly, and hysteretic losses were suspected to be the cause. However, investigations by Hongoh et al. (2006) showed that friction at the interfaces has a major influence. Plates of polypropylene (PP) and respectively polymethylmethacrylate (PMMA) having a thickness of $3 \mathrm{~mm}$ and three polished plates of 1-mm thickness being clamped together were subjected to the same ultrasonic vibrations. The thermographic measurements showed that the plate package heated up faster and that heat built up at the interfaces. Tolunay et al. (1983) used an ultrasonic welding machine for joining polysterol (PS) sheets and measured the temperature at the interface and inside the joining partners. The study showed that the temperature gradient at the interface was greater than in the interior and that heating of the workpiece emanated from the interface. In summary, it can be stated that the proportion of heating inside the material and at the interface is dependent on the material. With relatively soft plastics, the heating is caused mainly by hysteretic losses, whereas with harder plastics, the surface friction has a greater influence.

For parallel vibration, the following studies have been conducted. Wanske (2010) posited the thesis that the friction between a sonotrode and cardboard is mainly responsible for heating and not the damping losses within the material. Wanske (2010) measured the temperature of the cross-section of a material with a thermographic camera and found that the temperature increase started at the contact surface and then transferred to the entire cross-section. Stokes (1988) and Potente et al. (1987) provided approaches to an analytical model of the warm-up phase of friction welding. Both assumed that heating was caused entirely by Coulomb friction of the contacting partners. However, the calculated times were too short for both models, which the authors concluded was because of irregular surfaces and incomplete surface contact. Uebbing (1995) assumed that the too short times in the models by Stokes (1988) and Potente et al. (1987) were because the shear stresses induced by the friction force and the resulting damping losses in the material were ignored. Uebbing (1995) fixed the oscillator and one of the contacting partners at a low amplitude, so that only shearing occurred without relative movement. The measured temperatures were in good agreement with the FEM calculations. Erhard (1980) found that in addition to friction caused by adhesion, deformation mechanisms also contributed to material heating. 
Depending on the surface roughness and surface pressure, the latter was more or less pronounced.

The most important influencing factors on heating are the contact pressure, vibration amplitude, and direction of vibration of the sonotrode surfaces that come into contact with the cardboard. The influence of these factors on the heating of cardboard were examined in this study.

\section{EXPERIMENTAL}

An experimental setup for installation in a compression testing machine was developed, with which pressure on a $1 \mathrm{~cm} \times 1 \mathrm{~cm}$ area of the test material could be applied (Fig. 2). The maximum pressure in the gap when deep-drawing is $20 \mathrm{MPa}$, which was used in this study (Löwe et al. 2017). The pressure was increased non-equidistantly to have a higher resolution in the lower pressure range. For each of the four parameter combinations, 40 experiments were conducted and the pressure was calculated with the following equation,

$$
p(n)(\mathrm{MPa})=\frac{n^{2}}{80}
$$

where $p$ is the pressure and $n$ is the experiment number.

Typical industrial cardboard for tray forming was used in the experiments (Trayforma natura (TF), STORA ENSO, Stockholm, Sweden). It is a three-layered material of virgin-quality fiber made of sulphate pulp and chemithermomechanical pulp (CTMP) in the middle and sulphate pulp in the outside layers. The grammage and thickness were 350 $\mathrm{g} / \mathrm{m}^{2}$ and $460 \mu \mathrm{m}$. The initial moisture content under standard climate conditions in the laboratory $\left(23{ }^{\circ} \mathrm{C}\right.$ and $50 \%$ relative humidity) was determined to be $6.1 \% \pm 0.3 \%$ in accordance with EN ISO 287 (2009). Half of the test samples had an elevated moisture content that was reached by conditioning in a climate chamber (Model C2TAI, cavallo srl, Milano, Italy). Temperature and humidity were set to $40{ }^{\circ} \mathrm{C}$ and $85 \%$ with an accuracy of one decimal place, which corresponded to a moisture contents of $11.42 \pm 0.4 \%$. The weights of the conditioned and the kiln-dry material were measured on a precision scale (Secura313-1S, Sartorius, Göttingen, Germany). The moisture content immediately after the experiments was also recorded. The surface roughness of the material was $400 \mathrm{~mL} / \mathrm{min}$ (top) and $500 \mathrm{~mL} / \mathrm{min}$ (reverse) according to Bendtsen air leakage method (ISO 8791/2). All samples were cut out of the cardboard sheet in the same direction, so that the camera was looking in the cross direction (CD) of the material.

The load cell (Serie K (25 kN), GTM Gassmann, Bickenbach, Germany) had a precision of $5 \mathrm{~N}$ and was placed above the pressure jaw, so that the direct force could be measured. The pressure jaw was attached to the traverse, which was moved by two lifting spindles. The frame jaw was firmly anchored in the frame of the compression testing machine.

The rate at which the pressure was adjusted in every experiment was set high at 20 $\mathrm{mm} / \mathrm{min}$ to minimize falsification from the relaxation of the carton board. Thus, the time to set the pressure was less than $1 \mathrm{~s}$. The contact time between the sonotrode and material during the ultrasonic-assisted forming and joining processes is usually no longer than a few hundred microseconds. To capture all of the occurring effects, the oscillation time in all of the experiments was set to the relatively long period of $1.5 \mathrm{~s}$. The position that the pressure testing machine reached to set the pressure was maintained for the duration of the 
experiment. For the temperature measurement, a $1-\mathrm{mm}^{2}$ section of the material crosssection was measured with a thermographic camera (ImageIR 5320, Infratec, Dresden, Germany). During ultrasonic vibration, the temperature was recorded with a sampling frequency of $10 \mathrm{~ms}$ and resolution of 128 pixels $\times 160$ pixels. The temperature measurement was calibrated by heating a piece of the carton board in a bench oven (Zwick, Ulm, Germany) at $15{ }^{\circ} \mathrm{C}$ increments from $23{ }^{\circ} \mathrm{C}$ (standard temperature) to $220{ }^{\circ} \mathrm{C}$, while measuring the temperature with the thermographic camera. A compensation function was calculated from the specified and measured values to calculate the real temperatures.

The temperature data was used to determine the average temperature of the cardboard section, the temperature gradient of the average temperature, and the maximum temperature, which was calculated as the average temperature of four pixels in a square. The parameters of the full factorial design are shown in Table 1.

Table 1. Experimental Design for the Temperature Measurements

\begin{tabular}{|c|c|c|}
\hline Parameter & \multicolumn{2}{|c|}{ Level } \\
\hline Material & \multicolumn{2}{|c|}{ TF350 } \\
\hline Pressure (MPa) & \multicolumn{2}{|c|}{$0.0125-20$} \\
\hline Initial Material Moisture (\%) & 6.1 & 11.42 \\
\hline Amplitude $(\mu \mathrm{m})$ & 10 & 20 \\
\hline Oscillation Time (s) & \multicolumn{2}{|c|}{1.50} \\
\hline
\end{tabular}

The method for assessing the spread of the data points is shown in Fig. 1. The data points were fitted with a spline fit, which is easily implemented in MATLAB (The MathWorks, Natick, MA, USA), and the width of a corridor surrounding the fit which contained $95 \%$ of the data was specified. To calculate the width of the corridor, the axes have been standardized so that the largest value of each axis equals 1 . The width, which is given as a standardized value, is a measure of the goodness of the fit.

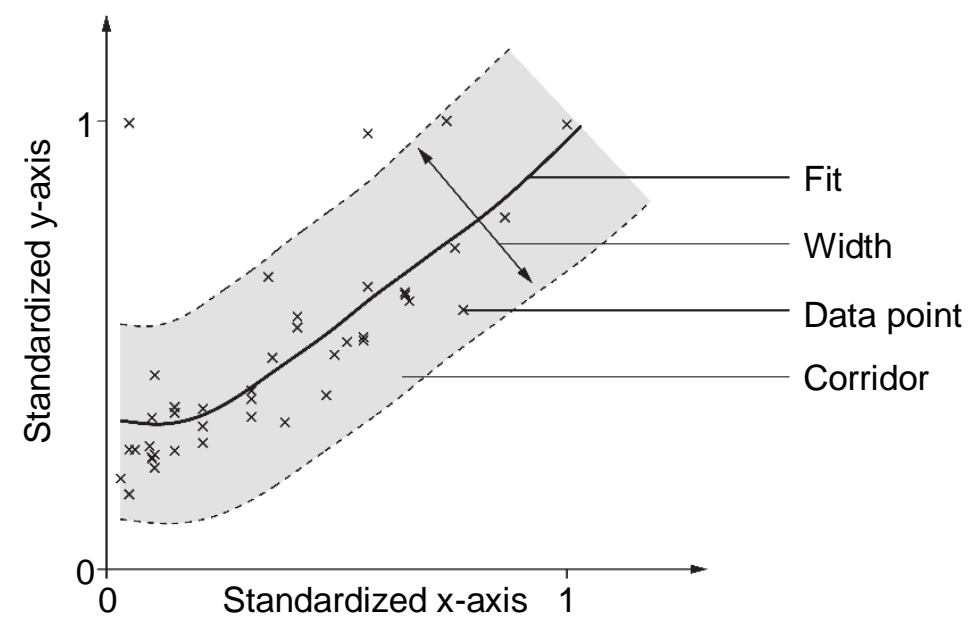

Fig. 1. Corridor surrounding a data fit, which contains $95 \%$ of the data points

Figure 2 shows how the equipment was set up to observe the heating effects of vibrations applied in the parallel and perpendicular directions. 


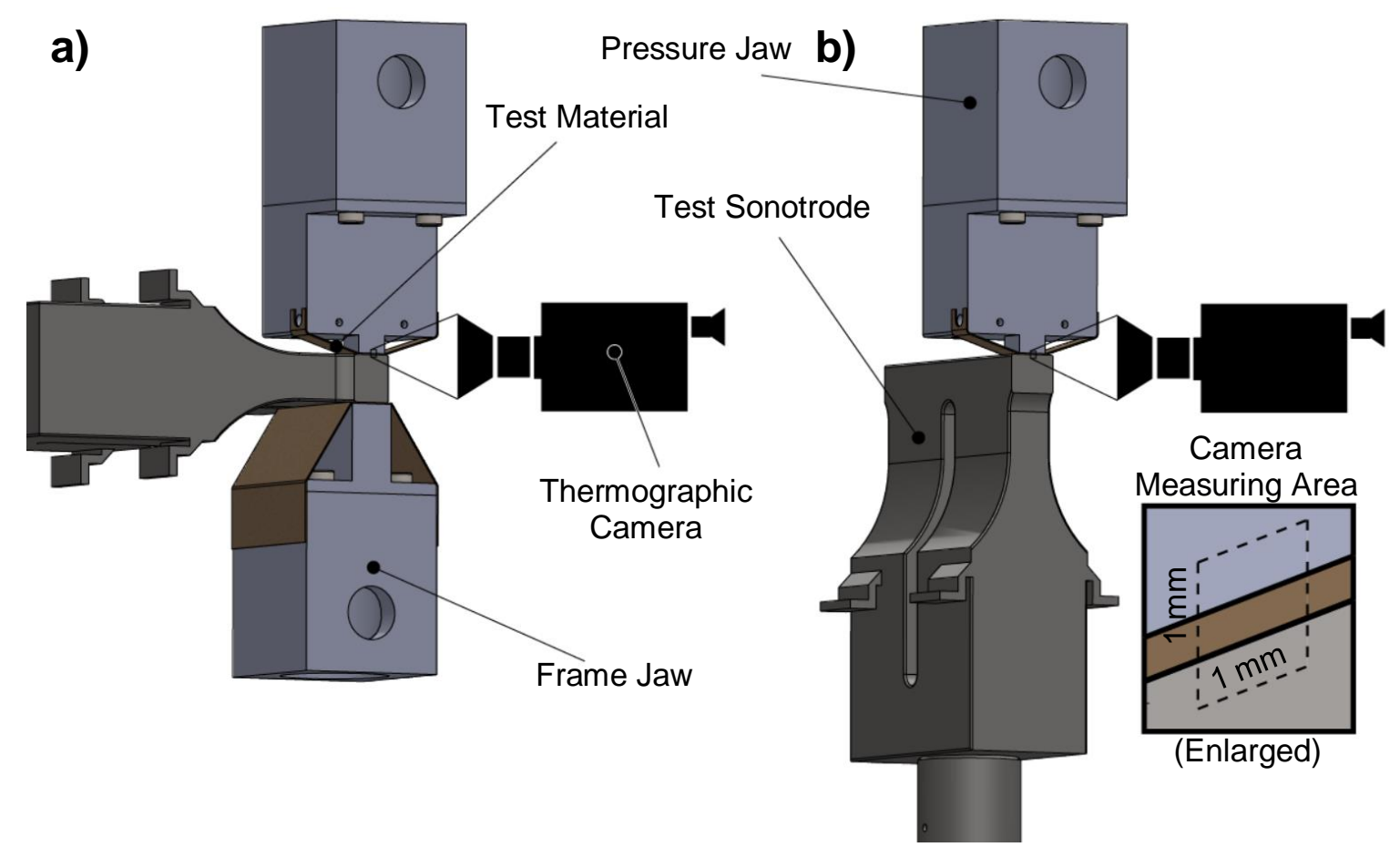

Fig. 2. Sketch of the measurement setup for heating with vibration, which was orientated parallel (a) and perpendicular (b) to the material surface (sample holder not shown for sake of clarity)

The end positions of the vibrating mode of the test sonotrode are shown in Fig. 3. The test surface for vertical vibration remained flat during the oscillation period. For the test surface for parallel vibration, the amplitude ratio in the $\mathrm{Y}$ - and Z-directions was approximately $1 \%$, which can be assumed to be flat with sufficient accuracy. Both contact surfaces were polished with a roughness value of $0.2 \mu \mathrm{m}$ to $0.4 \mu \mathrm{m}$.
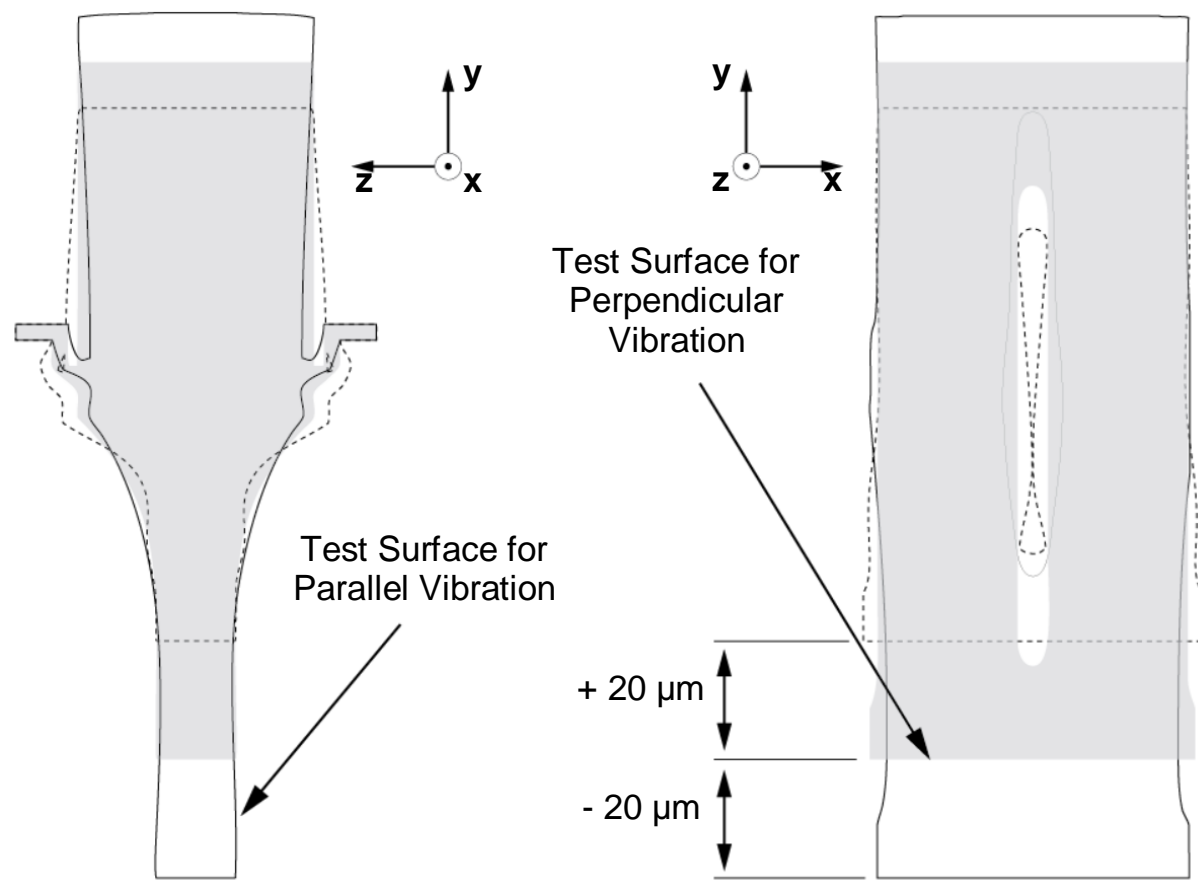

Fig. 3. Vibrating mode of the test sonotrode (1000x enlarged) 
There was a pressure decrease shortly after the start of the measurement. Figure 4 shows pressure curves at $1 \mathrm{MPa}$ and $5 \mathrm{MPa}$ that illustrate this phenomenon well. The reference curves, which were recorded without ultrasonic vibrations, show a slight decrease of the pressure due to the unavoidable relaxation of the cardboard. Four other curves show the pressure course with perpendicular and parallel direction of vibration. The pressure drop is higher with increasing starting pressure and with the perpendicular vibration. Presumably, this effect was caused by the plastic decrease in the material thickness and the accompanying loss of contact for parts of the oscillation period. The plastic part of the deformation and the loss of thickness are higher with increasing compressive strain, which in turn is increased by the starting pressure and the superimposed compression caused by the vibration. The proportion of the vibration amplitude in the thickness direction is greater with the vertical vibration than with the parallel one and therefore also the pressure drop.

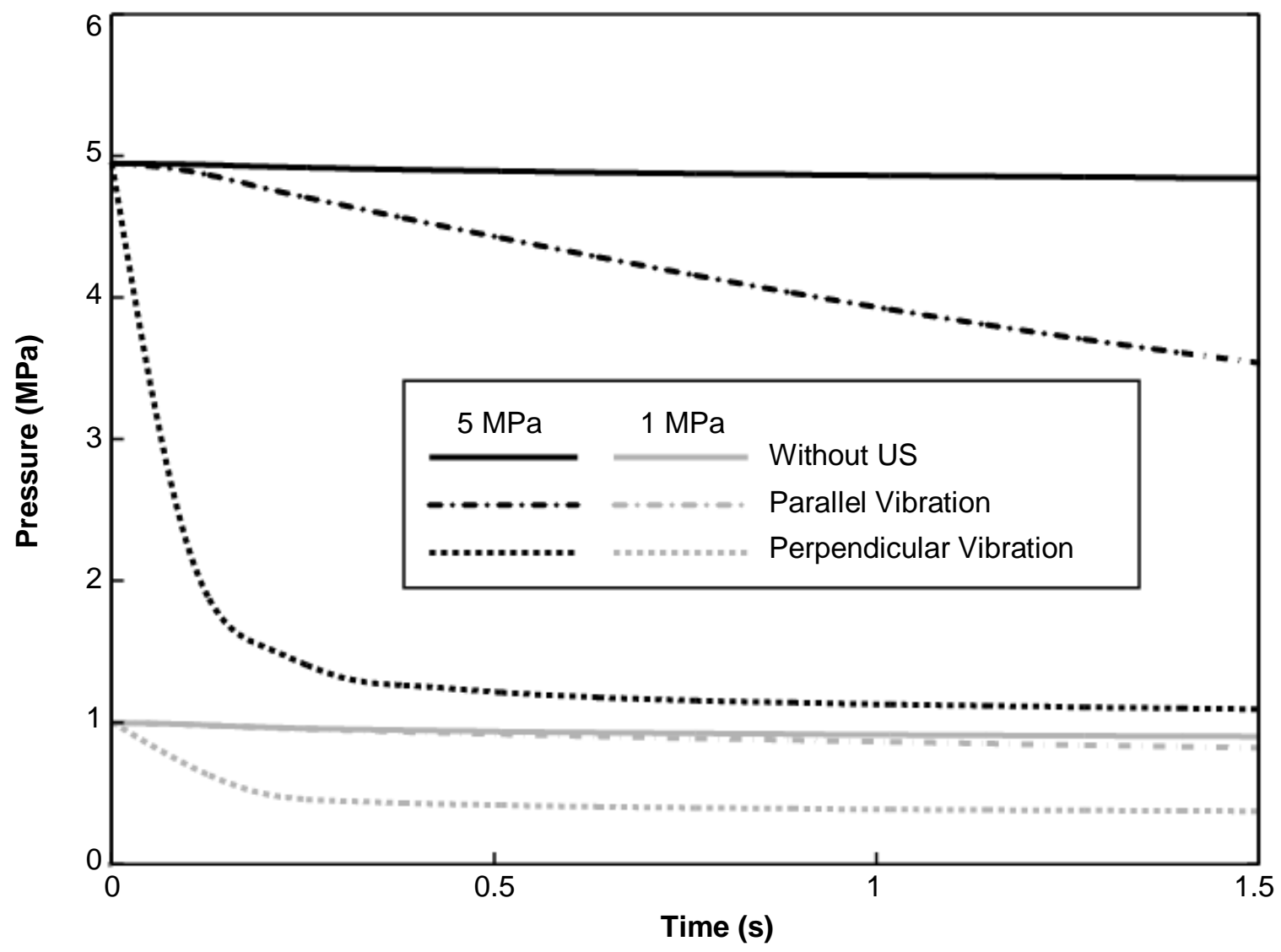

Fig. 4. Development of the pressure at different starting values and vibration modes as a function of time; material: TF 350; amplitude: $20 \mu \mathrm{m}$

Bach (2014) made a similar observation while recording the ultrasonic sealing process of two polymeric foils with a high-speed camera. At the beginning, the two foils had a combined thickness of $600 \mu \mathrm{m}$, which decreased to approximately $390 \mu \mathrm{m}$ at the end of the process. The pressure was kept constant with a feedback control by moving the sonotrode downwards. At that time Bach believed that the sonotrode is always in touch with the material but the images showed the opposite (Fig. 5). 




Fig. 5. Two images of a high-speed recording of an ultrasonic sealing process at $20 \mathrm{kHz}$ : (a) at the beginning and (b) after $0.3 \mathrm{~s}$ (with permission of Dr.-Ing. Sascha Bach)

Bach (2014) also found that the distance between the material and vibrating sonotrode increased because of deformation of the sonotrode mounting. As a result, the pressure decreased. A sufficiently high contact pressure could prevent this effect. Theoretically, the sonotrode can be one amplitude at most away from the material, but in practice, it was only approximately $30 \%$ of this distance in his experiments.

A defined application of the pressure with ultrasonic oscillation switched on cannot be realized. The time to build up the pressure force varies and is not reproducible. Therefore, the load was applied first and then the ultrasound was turned on.

The sonotrode surface was given enough time between the experiments to cool down to a maximum of $3{ }^{\circ} \mathrm{C}$ above the standard temperature. This was done to avoid a falsification of the measurement because of heat transfer from the sonotrodes to the cardboard. It was assumed that the heat flow into the sonotrodes in both experimental arrangements in Fig. 2 was the same and both setups could be compared with each other. This assumption was based on FEM calculations of the welding of aluminum strips (Elangovan et al. 2009; Panda 2010) concerning the heat transfer into the sonotrode and anvil and the heat conduction inside of the tools during the process. The calculations show that heating of the sonotrodes only occurs in the immediate vicinity of the contact surface. This was attributed to frictional phenomena on the surface and local deformations inside the sonotrode. The geometry of the sonotrode had no remarkable influence on heating.

\section{RESULTS AND DISCUSSION}

\section{Temperature Development Over Time}

The contact pressure notably influenced the heating of the material. Because it decreased shortly after the start, the temperature gradient at the beginning of the ultrasonic vibration reached a maximum before it decreased to a relatively constant value near zero (Fig. 6b and 6d). Thus, overly rapid heating and burning of the material was avoided. Another influencing factor was the vibration mode. Figures $6 \mathrm{a}$ and $6 \mathrm{c}$ show the temperature curves along a line in the Z-direction at $5 \mathrm{MPa}$ and $10 \mathrm{MPa}$, respectively. It was seen that vertical vibration heated the material symmetrically to the middle layer of the material, while with parallel vibration, the heat was first induced in the layers that were near the sonotrode surface. This was most evident at a pressure of $10 \mathrm{MPa}$. Although the peak temperature with parallel vibration was approximately twice as high as that with vertical vibration, the temperature gradient of the entire section was smaller. One possible reason could have been the size of the heating zone. In the case of vertical oscillation, a 
deformation gradient formed over the entire thickness of the material, whereas in the case of parallel oscillation, only the layers close to the surface heated up. The difference in mass between the two areas led to the different temperature gradients. It appeared that mainly dissipative effects in the interior caused material heating with vertical vibration. In the case of parallel vibration, friction at the surface was mostly responsible for heating, but an accurate assessment can only be made after deeper examination of the mechanics. The maximum temperature with parallel vibration was found at approximately $90 \%$ of the material thickness and not directly at the interface. This was because of heat transfer to the sonotrode.

a)

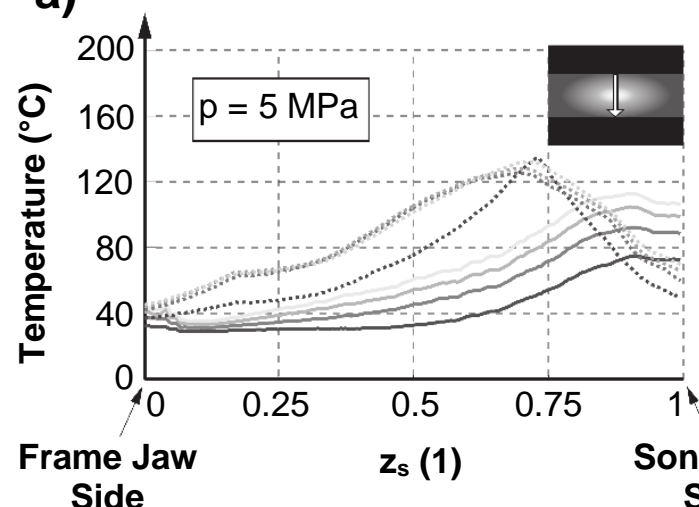

c)

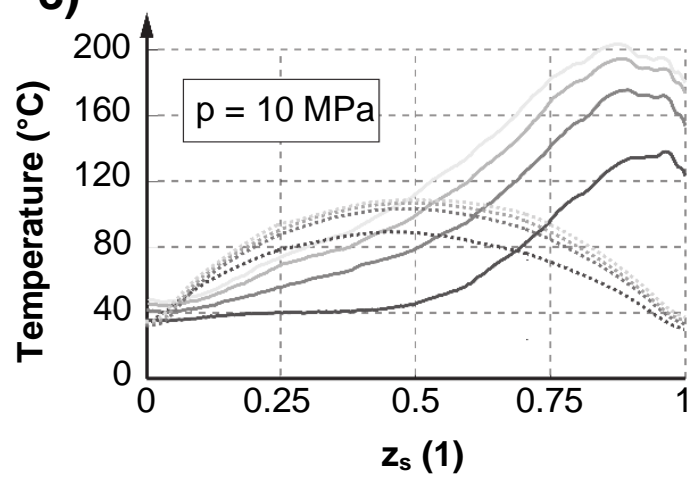

\begin{tabular}{|c|c|}
\hline $\begin{aligned} \bar{\Phi}-t & =1.50 \mathrm{~s} \\
\overline{\bar{\sigma}}-\mathrm{t} & =1.125 \mathrm{~s} \\
\frac{\sqrt{\sigma}}{\mathrm{\sigma}}-\mathrm{t} & =0.75 \mathrm{~s} \\
-\mathrm{t} & =0.375 \mathrm{~s}\end{aligned}$ & 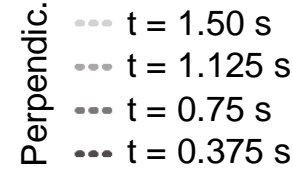 \\
\hline
\end{tabular}

b)

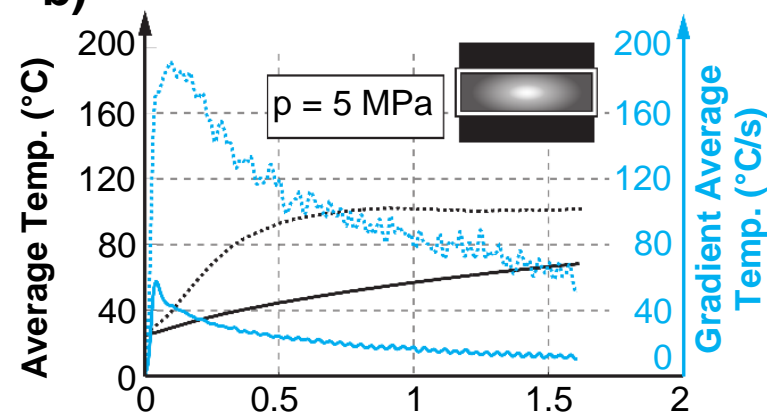

Time (s)

Side

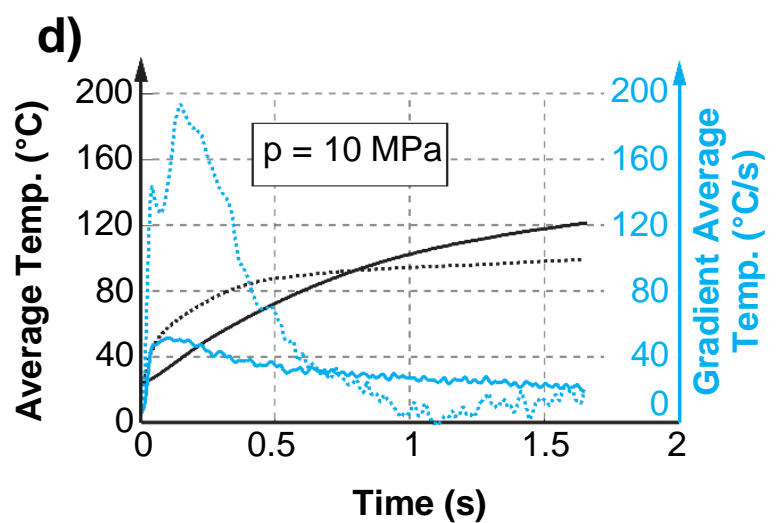

Fig. 6. (a and c) Heat measured along a line in the Z-direction with standardized z-coordinate $z_{s}=\boldsymbol{z} /$ Mat.Thkns $;(b$ and d) course of the average temperature and the gradient of the average temperature of the entire cross-section; experimental parameters: amplitude $=10 \mu \mathrm{m}$, material moisture $=6.1 \%$, and initial pressure $=5 \mathrm{MPa}(\mathrm{a}$ and $\mathrm{b})$ and $10 \mathrm{MPa}(\mathrm{c}$ and $\mathrm{d}$ ) 


\section{Initial Temperature Gradient}

For parallel vibration with an amplitude of $10 \mu \mathrm{m}$, the pressure could only be increased up to $12 \mathrm{MPa}$ because at higher pressures the generator could no longer provide the starting power to build up a stationary vibration. The amplitude is regulated in the generator based on the provided power. A low amplitude in conjunction with high external loads can cause start-up difficulties.

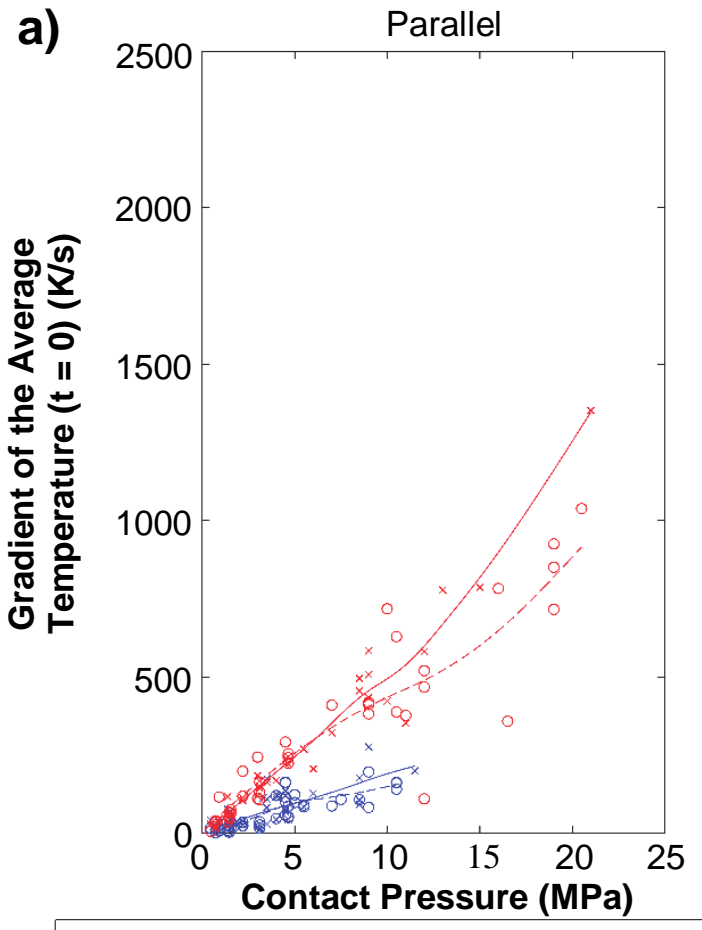

$$
\begin{aligned}
& \longrightarrow \quad \text { Mat. moist. }=11.42 \% ; \text { Ampl. }=10 \mu \mathrm{m} \\
& \text { Width }=0.05 / 0.17 \\
& \times \quad \text { Mat. moist. }=11.42 \% ; \text { Ampl. }=20 \mu \mathrm{m} \\
& \quad \text { Width }=0.07 / 0.13
\end{aligned}
$$

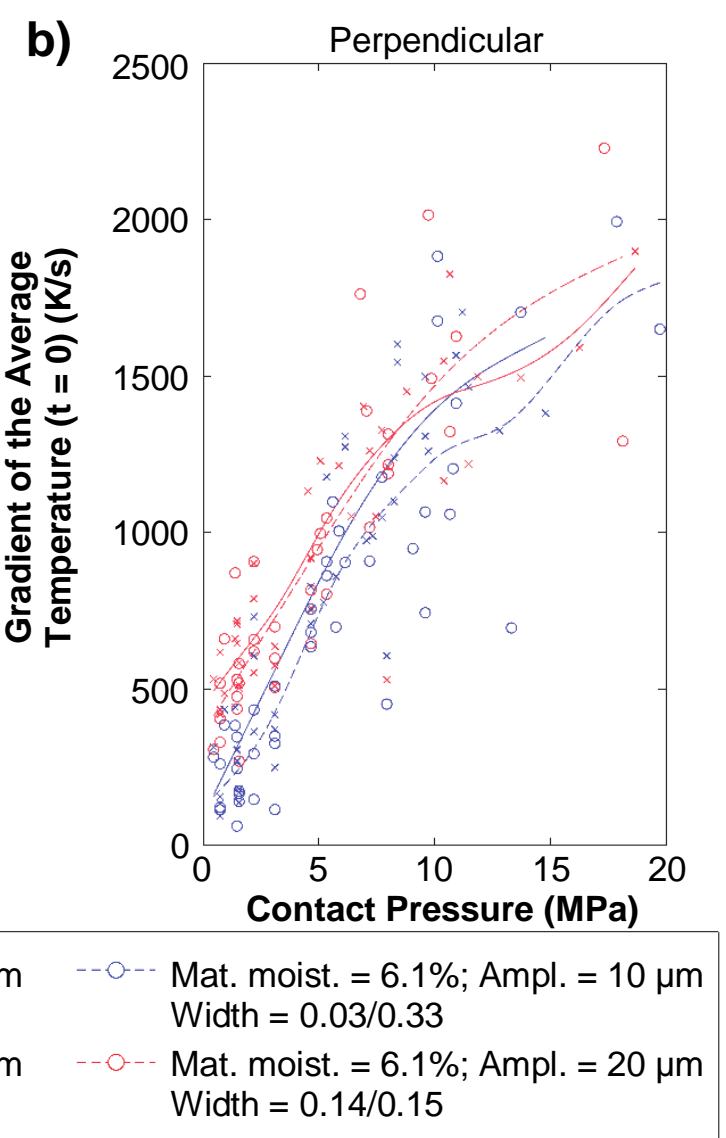

Fig. 7. Gradient of the average temperature of the material cross section at $t=0 \mathrm{~s}$ as a function of the amplitude, material moisture, vibration mode, and pressure: (a) parallel vibration and (b) perpendicular vibration

The width of the fit corridor could be quite large because of the inhomogeneous distribution of the density over the material, which is typical for cardboard. The temperature gradient of a data point with low density rose faster than that of a data point with high density. Additionally, the fluctuating pressure drop at the beginning of the experiments broadened the corridor even more.

The moisture content of the material had hardly any influence, which is explained in the section "moisture content".

In the case of parallel vibration, the temperature increase depended remarkably on the ultrasonic amplitude because the heat generated by the frictional force was proportional to the traveled distance, i.e., the oscillation amplitude. The amplitude had less influence on the vertical vibration. As was described above, the material was simultaneously heated and compressed when the ultrasound was switched on. This phenomenon occurred 
independently of the oscillation amplitude, so that the temperature gradients at the amplitudes of $10 \mu \mathrm{m}$ and $20 \mu \mathrm{m}$ only resulted in relatively small differences.

In the case of vertical vibration, the temperature gradient did not start at $0 \mathrm{~K} / \mathrm{s}$ as with the parallel vibration mode, but at $200 \mathrm{~K} / \mathrm{s}(10-\mu \mathrm{m}$ amplitude) and $500 \mathrm{~K} / \mathrm{s}(20-\mu \mathrm{m}$ amplitude). This was because the material was always compressed at least one amplitude width, even if there was no pressure. In the case of parallel vibration, there was no friction on the surface without pressure and thus no heating.

The vertical vibration mode heated the material faster than the parallel mode, as is shown in Fig. 6. Further research is needed to determine the exact cause of this.

A linear dependence of the contact pressure was recognizable with the parallel vibration mode because the Coulomb friction force and thus the heat development were proportional to the pressure. The course of vertical vibration was degressive. Bach (2014) made the same observation when heating polyethylene with vertically directed ultrasonic vibration. Bach (2014) explained this phenomenon was because of the larger initial strain at higher pressures, which may extend into the nonlinear viscoelastic or even plastic ranges. When the proportion of plastic strain to total strain increased, the material was no longer deformed by vibration to the extent of linear viscoelastic materials because the elastic springback decreased. Erhard (2008) used the hysteretic stress-strain behavior of polymers as an explanation for the degressive course. In the linear-viscoelastic region, the stressstrain behavior of the material can be described with an elliptical hysteresis. In contrast, in the case of non-linear viscoelastic behavior (Fig. 8), which can be caused by larger prestrains, the course deviates from the ideal elliptical shape. The share of dissipation, which characterizes the proportion of energy converted to heat, was reduced compared with the stored energy. The dissipation of a non-linear-viscoelastic material increased with an increasing pressure, but not as fast as with a linear-viscoelastic material.

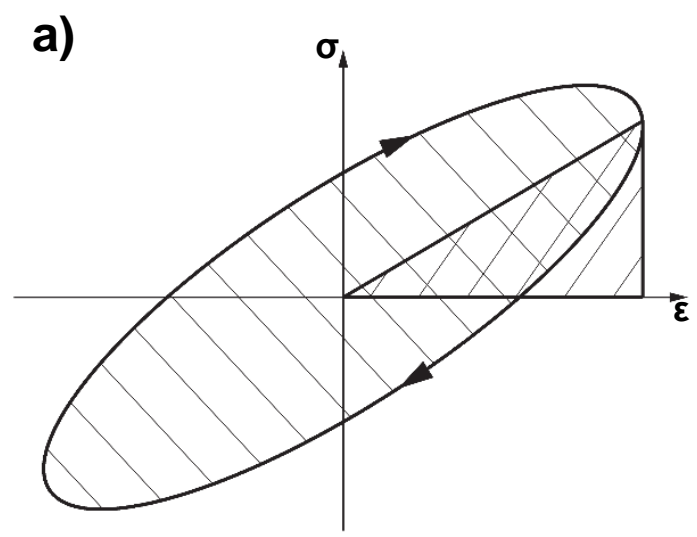

$\square$ Stored Work

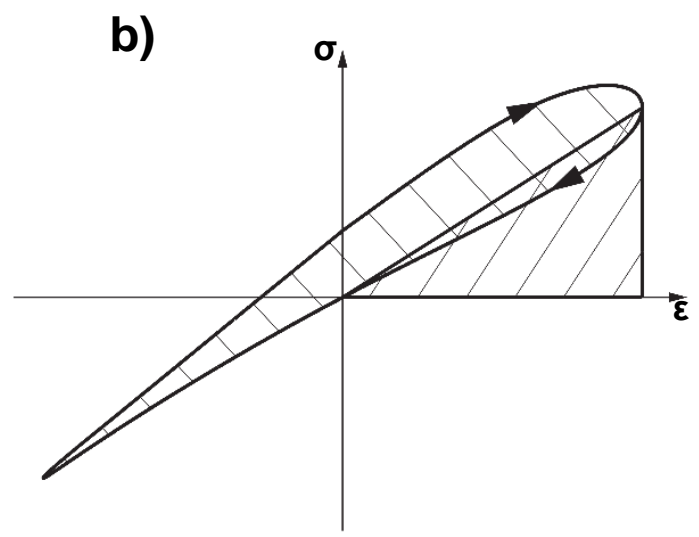

Lost Work

Fig. 8. Stress-strain hysteresis with sinusoidal strain for (a) linear-viscoelastic behavior and (b) non-linear viscoelastic behavior (Erhard 2008)

\section{Maximum Temperature}

The thermographic camera did not measure values outside of the set measuring range (up to $215^{\circ} \mathrm{C}$ ). Higher temperatures were attained, but this was usually not desirable 
because the decomposition temperature of the major component of the cardboard (cellulose) is approximately $220{ }^{\circ} \mathrm{C}$. At that point, browning and charring commence, which renders the later formed part useless.

a)

)

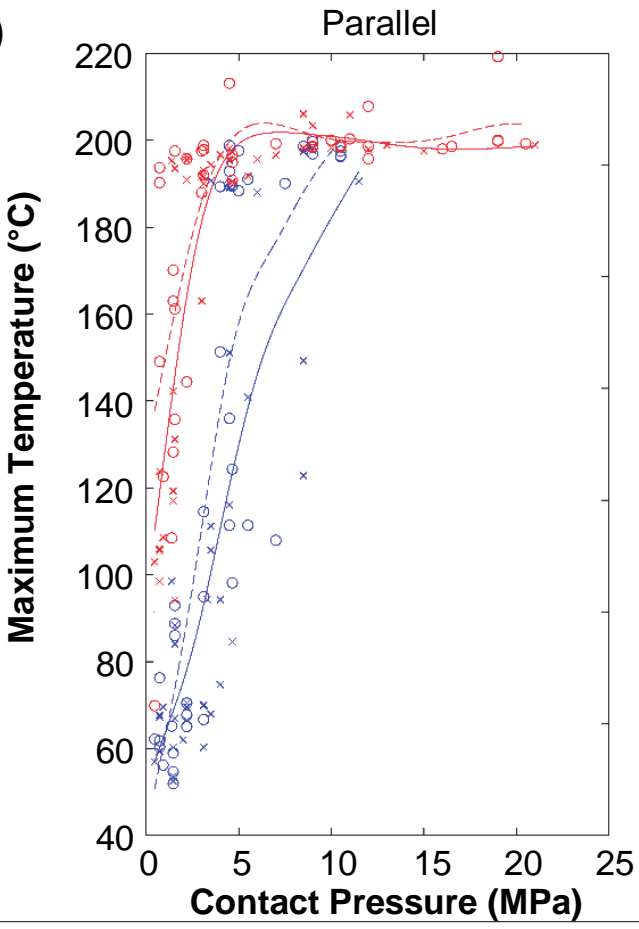

Mat. hum. = 11.42\%; Ampl. = $10 \mu \mathrm{m}$ Width $=0.32 / 0.24$

Mat. hum. $=11.42 \% ;$ Ampl. $=20 \mu \mathrm{m}$ Width $=0.18 / 0.04$ b)

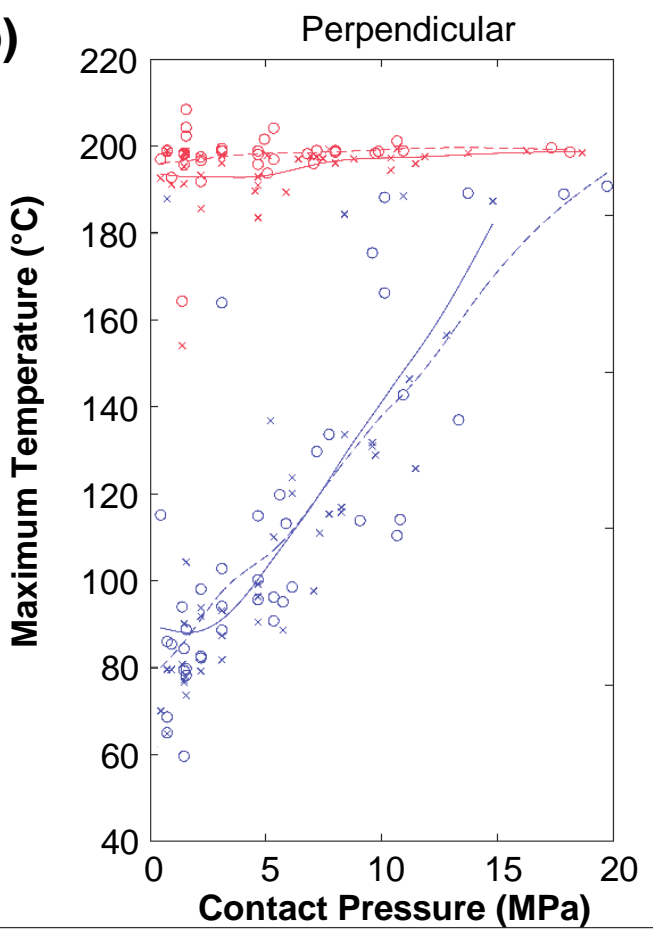

Fig. 9. Maximum temperature during 1.5-s heating as a function of the direction of vibration, material moisture, amplitude, and pressure for (a) parallel and (b) perpendicular vibration

The width of the fit corridors of the experiments with perpendicular vibration and a high amplitude were relatively small, because often only the upper boundary of the measurement range was recorded.

The amplitude had a decisive influence on the attainment of the decomposition temperature. It was always reached with vertical vibration at the $20-\mu \mathrm{m}$ amplitude, even at low pressures, although the amplitude did not influence the initial temperature gradient. With parallel vibration, a certain contact pressure was needed so that the frictional force could act.

The maximum temperature, with the exception of small pressures, was reached fastest with parallel vibration, although the heating rate and average temperature with vertical vibration were higher. The explanation for this is shown in Fig. 6.

\section{Moisture content}

An obvious measure to prevent the material from burning would be to increase the moisture content, but there was no discernible difference between the material in standard climate and after climatic conditioning with $40^{\circ} \mathrm{C}$ and $85 \% \mathrm{RH}$. To ascertain the reason for 
this, first the energy for evaporating the moisture in the material was compared with the energy for heating the cardboard to the maximum temperature $\left(215^{\circ} \mathrm{C}\right)$ and secondly the moisture content was measured immediately after the experiments.

The energies for heating the material resp. for evaporating the additional water gained by conditioning were calculated as

$$
\begin{aligned}
& m_{c b}=A_{c b} \cdot g \\
& c_{c b}=(4.11 \cdot T+1033) \\
& E_{c b}=m_{c b} \cdot\left[c_{c b}\left(215^{\circ} \mathrm{C}\right) \cdot 215^{\circ} \mathrm{C}-c_{c b}\left(23^{\circ} \mathrm{C}\right) \cdot 23^{\circ} \mathrm{C}\right]=13.51 \mathrm{~J} \\
& E_{w 100^{\circ} \mathrm{C}}=m_{c b} \cdot\left(m c_{c}-m c_{s t}\right) \cdot c_{w} \cdot\left(100^{\circ} \mathrm{C}-23^{\circ} \mathrm{C}\right)=0.61 \mathrm{~J} \\
& E_{w e v}=m_{c b} \cdot\left(m c_{c}-m c_{s t}\right) \cdot H_{e v}=4.26 \mathrm{~J}
\end{aligned}
$$

where $m_{c b}$ is the mass of the cardboard, $A_{c b}$ is the area of the test sample $\left(1 \mathrm{~cm}^{2}\right), g$ is the grammage $\left(350 \mathrm{~g} / \mathrm{m}^{2}\right), c_{c b}$ is the specific heat capacity of Trayforma natura in $\mathrm{J} /(\mathrm{kg} \cdot \mathrm{K})$ (Wallmeier (2015)), $T$ is the temperature in ${ }^{\circ} \mathrm{C}, E_{c b}$ is the energy for heating the material to $215^{\circ} \mathrm{C}, E_{w 100^{\circ} \mathrm{C}}$ is the energy for heating the additional water to $100{ }^{\circ} \mathrm{C}, m c_{c} / m c_{s t}$ are the moisture contents after conditioning / in the standard climate $(11.42 \% / 6.08 \%), c_{w}$ is the specific heat capacity of water $(4.18 \mathrm{~kJ} / \mathrm{kg} / \mathrm{K}), E_{w e v}$ is the energy for evaporating the additional water, and $H_{e v}$ is the heat of evaporation for water at $100{ }^{\circ} \mathrm{C}(2.257 \mathrm{MJ} / \mathrm{kg})$. The energy for heating and evaporating the water is about one third of the energy for heating the cardboard, which means that the moisture content should have a significant influence on the heating behavior.

The matter can be examined more closely by measuring the moisture content, which is shown in Fig. 10a,b as a function of the contact pressure, the vibration mode, and the conditioning (standard climate resp. $40^{\circ} \mathrm{C}$ and $85 \% \mathrm{RH}$ ). In addition, measurements with an oscillation time of $0.2 \mathrm{~s}$ were conducted to get an indication of the time course of the moisture content. The material moisture in the standard climate and after conditioning is shown for comparison.

It can be seen, that the difference between an oscillation time of $0.2 \mathrm{~s}$ and $1.5 \mathrm{~s}$ is immense, which means that the removal of the water takes longer than $200 \mathrm{~ms}$. There is a significant loss of moisture even at the lowest pressure and the shortest oscillation time, because the water is removed from the material in two ways. First, by evaporation, and secondly, by extrusion (Fig. 10c). The differences between the initial moisture contents and the ones at a contact pressure of $1 \mathrm{MPa}$ and an oscillation time of $0.2 \mathrm{~s}$ indicate that a non-negligible amount of the water is removed by extrusion in the first $200 \mathrm{~ms}$, because this period of time is too short for heating and evaporating it. The parallel vibration mode conveys less water to the outside than the perpendicular one, because, firstly, the proportion of amplitude in the thickness direction of the material is much smaller than that of the vertical vibration and therefore less moisture is pressed out of the material, and secondly because less heat is generated inside the material.

The reason for the only marginal differences between the moisture contents in Fig. 7 and 9 , which exist despite the proven amount of water in the material and the relatively large energy necessary to evaporate it, is because the water is probably not evenly distributed in the material. The sample dries faster on the outer edge than in the center and since the thermographic camera only covers the border area, the real impact of the moisture content is not detected properly. An alternative to thermography would be the measurement with thermocouple wires in the center of the material, which brings about other problems 
though, like the distortion because of the thermal inertia of the wire or the complicated application of the wire inside the material.
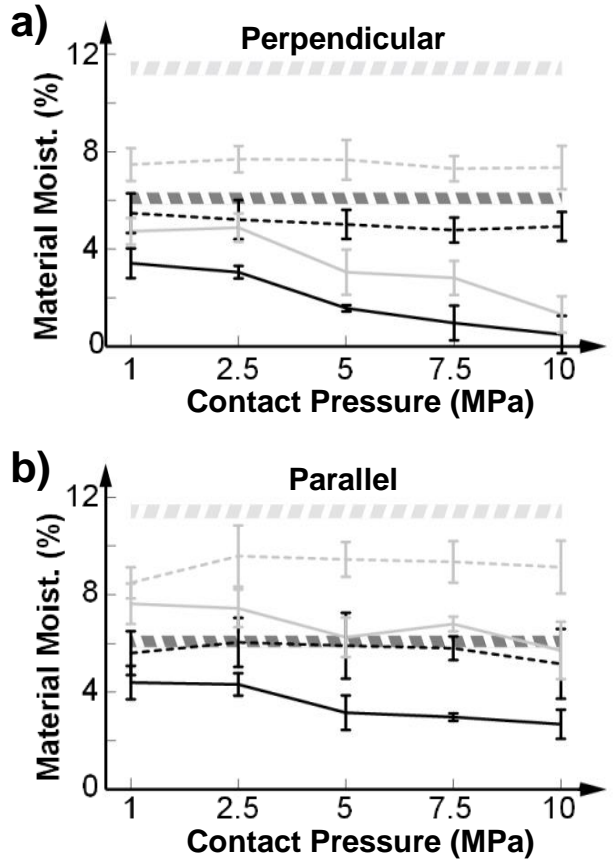

c)

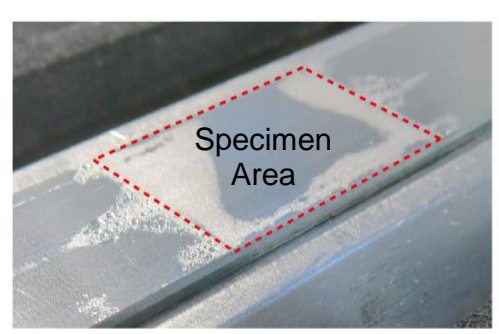

- Standard Climate, $1.5 \mathrm{~s}$

- Conditioned, $1.5 \mathrm{~s}$

... Standard Climate, $0.2 \mathrm{~s}$

... Conditioned, $0.2 \mathrm{~s}$ Initial Moisture, Conditioned III Initial Moisture, St. Climate

Fig. 10. Moisture content before and after the experiment as a function of the contact pressure, the vibration mode and duration, and the conditioning. Vibration amplitude was set to $20 \mu \mathrm{m}$. a) perpendicular vibration b) parallel vibration c) image of extruded water

\section{CONCLUSIONS}

1. The pressure began to drop a few milliseconds after switching on the ultrasound. This effect was more pronounced with vertical vibration because of plastic compression of the cardboard by the sonotrode and the associated contact loss during parts of the oscillation period. With parallel vibration, only a small amount acted in the vertical direction with the above-mentioned effects.

2. With vertical vibration, heating started in the center of the material, whereas heating started in the boundary region between the sonotrode and material with parallel vibration. Presumably, dissipative effects in the interior and friction losses at the surface caused these characteristics.

3. The decomposition temperature of the cardboard was reached faster with parallel vibration than with vertical vibration, although the average temperature was lower with parallel vibration. The reason for this might have been the size of the heating zone.

4. In the case of parallel vibration, the temperature increase depended remarkably on the ultrasonic amplitude because the heat generated by the frictional force was proportional to the traveled path, i.e., the oscillation amplitude. The amplitude had less influence with vertical vibration. 
5. The initial temperature gradient with parallel vibration was proportional to the pressure because the frictional force and thus heat development were proportional to the pressure. With vertical vibration, the course was degressive because of the nonlinear viscoelastic material behavior.

6. Parallel vibration was not ideal for deep-drawing with the sonotrodes because it only heated the near-surface areas and easily burned the material. Vertical vibration was more suitable because heating was uniform across the thickness.

7. The remaining amount of water in the material after the ultrasonic treatment depends strongly on the experimental parameters. The influence of the material moisture on the heating could not be detected by thermography measurements, as only the edge area of the sample is measured and the moisture is presumably not distributed evenly over the sample surface.

\section{ACKNOWLEDGMENTS}

We acknowledge support by the Open Access Publication Funds of the SLUB/TU Dresden.

\section{REFERENCES CITED}

Bach, S. (2014). Untersuchung der Vorgänge und Einflüsse beim Ultraschallfügen Flexibler Polymerer Packstoffe [Investigation of the Processes and Influences During Ultrasound Joining of Flexible Polymer Packaging Materials], TU Dresden, Dresden, Germany.

Benatar, A. (1989). "Ultrasonic welding of thermoplatics in the near-field" Polymer Eng. Sc. 29(23), 1689-1698.

Bleck, W. (2017). Handbuch Stahl: Auswahl, Verarbeitung, Anwendung [Steel: Selection, Processing, Applications], Carl Hanser Verlag, Munich, Germany, ISBN: 3446449612.

Chernyak, B. Y. (1973). "The process of heat formation in the ultrasonic welding of plastics," Weld. Prod.+ 8, 87-91.

Elangovan, S., Semeer, S., and Prakasan, K. (2009). "Temperature and stress distribution in ultrasonic metal welding-A FEA-based study," J. Mater. Process. Tech. 209(3), 1143-1150. DOI: 10.1016/j.jmatprotec.2008.03.032

Erhard, G. (1980). Zum Reibungs- und Verschleißverhalten von Polymerwerkstoffen [For the Friction and Wear Behavior of Polymer Materials], Ph.D. Dissertation, Universität Karlsruhe, Karlsruhe, Germany.

Erhard, G. (2008). Konstruieren mit Kunststoffen, $4^{\text {th }}$ Ed., [Constructing with Plastics], Carl Hanser Verlag, Munich, Germany.

Goodfellow (2018), "Polypropylen material information," (www.goodfellow.com/E/Polypropylene.html), Accessed 26 Nov 2018.

Hongoh, B., Miura, H., Ueoka, T., and Tsujino, J. (2006). "Temperature rise and welding charcteristics of various-frequency ultrasonic plastic welding systems," JPN. J. Appl. Phys. 45, 4806-4811. DOI: 10.1143/JJAP.45.4806

Kleineheismann, S. (2009). "Determination of the tribological material indices of thermoplastic granulates," J. Plastics Techn. 5(3), 201-219

Hauptmann, M. (2010). Die gezielte Prozessführung und Möglichkeiten zur 
Prozessüberwachung beim mehrdimensionalen Umformen von Karton durch Ziehen [The specific process management and possibilities for process monitoring in the multi-dimensional forming of cardboard by deep-drawing], Ph.D. Disseration ,TU Dresden, Dresden, Germany.

Hauptmann, M. (2017). Neue Einsatzpotentiale naturfaserbasierter Materialien in der Konsumgüterproduktion durch die technologische Entwicklung des Ziehverfahrens am Beispiel der Verpackung [New application potential of natural fiber based materials in the consumer goods production through technological development of the deep-drawing process using the example of packaging], postdoctoral thesis, TU Dresden, Dresden, Germany.

Lazan, B. J. (1969). "Damping of materials and members in structural mechanics," Pergamon Press, Great Britain

Lenske, A., Müller, T., Penter, L., Schneider, M., Hauptmann, M., and Majschak, J.-P. (2017). "Evaluating the factors influencing the friction behavior of paperboard during the deep drawing process," BioResources 12(4), 8340-8358.

DOI: 10.15376/biores.12.4.8340-8358

Löwe, A., Hofmann, A., and Hauptmann, M. (2017). "The use and application of ultrasonic vibrations in the 3D deformation of paper and cardboard," J. Mater. Process. Tech. 240, 23-42. DOI: 10.1016/j.jmatprotec.2016.09.006

Niskanen, K. (1998). Paper Physics (Papermaking Science and Technology), Fapet Oy, Helsinki, Finland.

Panda, M. R. (2010). A Numerical and Experimental Approach to Study the Parametric Effect of Ultrasonic Welding, Ph.D. Dissertation, National Institute of Technology, Rourkela, India.

Potente, H., Michel, P., and Ruthmann, B. (1987). "Eine Analyse des Vibrationsschweissens [An analysis of vibration welding]," Kunststoffe, 711-716.

Potente, H. (2004). Fügen von Kunststoffen [Joining of Plastics], Carl Hanser Verlag, Munich, Germany.

Sperling, L. (2006). "Glass-rubber transition behavior," in: Introduction to Physical Polymer Science, John Wiley \& Sons Inc., Hoboken, New Jersey, pp. 349-426.

Stokes, V. K. (1988). "Vibration welding of thermoplastics. Part II: Analysis of the welding process," Polym. Eng. Sci. 28(11), 728-739. DOI: 10.1002/pen.760281105

Tolunay, M. N., Dawson, P., and Wang, K. K. (1983). "Heating and bonding mechanisms in ultrasonic welding of thermoplastics," Polym. Eng. Sci. 23(13), 726-733. DOI: $10.1002 /$ pen.760231307

Uebbing, M. (1995). Berechnungsmöglichkeiten und Qualitätssicherung beim Vibrationsschweißen [Calculation Options and Quality Assurance in Vibration Welding]," DVS-Berichte, Düsseldorf, Germany.

Wallmeier, M. (2015). "Explicit FEM analysis of the deep drawing of paperboard," Mechanics of Materials 89, 202-215, DOI:10.1016/j.mechmat.2015.06.014

Wanske, M. (2010). Hochleistungs-ultraschallanwendung in der Papierindustrie Methoden zur Volumenschonenden Glättung von Oberflächen [High-perforamnce Ultrasonic Application in the Paper Industry - Methods for Volume-saving Smoothing of Surfaces], Ph.D. Disseration, TU Dresden, Dresden, Germany.

Article submitted: Aug. 2, 2018; Peer review completed: Oct. 20, 2018; Revised version received and accepted: March 27, 2019; Published: March 28, 2019.

DOI: 10.15376/biores.14.2.3975-3990 


\section{APPENDIX}

In Fig. S1, four parameters that determine the heating in contact with highfrequency vibrating surfaces are shown for four common thermoplastics (polypropylene (PP), polyethylene low and high density (PE-LD, PE-HD), polystyrol (PS)), the cardboard used in this publication (Trayforma natura 350 (TF natura 350) and steel. The parameters are the thermal conductivity, the specific heat capacity, the dissipation factor at $20 \mathrm{kHz}$, which is a measure for damping losses, and the dynamic coefficient of friction against polished steel. Except for the coefficient of friction, which is subject to large fluctuations, the parameters for the thermoplastics and the cardboard are of the same magnitude, whereas there are major differences to metals and metal alloys like steel.

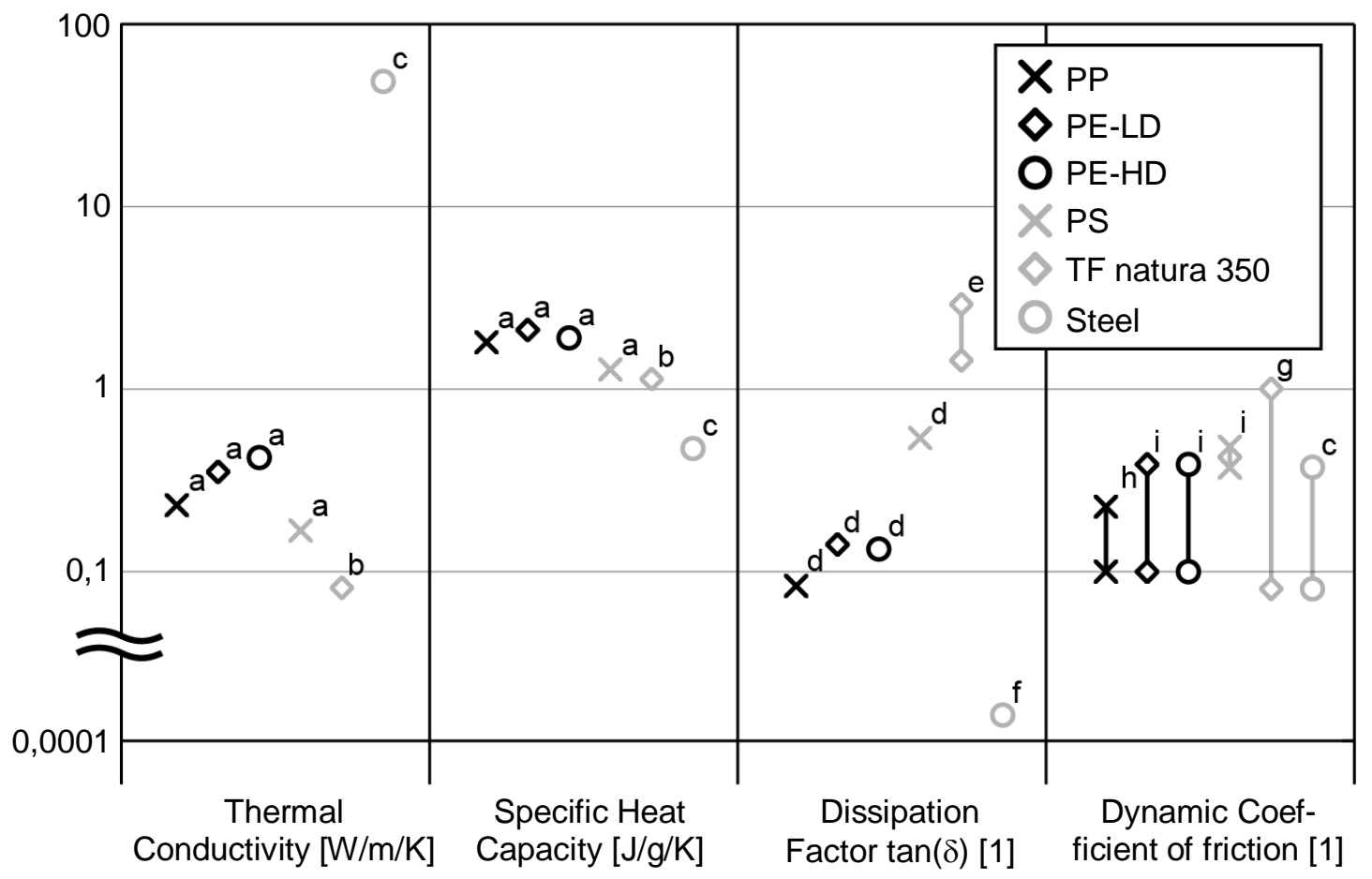

Fig. S1. Selected material parameters for common thermoplastics, the cardboard used in this publication, and steel. Sources: a Potente (2004) b Wallmeier (2015) c Bleck (2017) d Benatar (1989) e Own measurement f Lazan (1969) g Lenske et al. (2017) h Goodfellow (2018)

i Kleineheismann (2009) 